http:/www.journals.zu.edu.eg/journalDisplay.aspx?Journalld=1\&queryType=Master

\title{
PHYSICOCHEMICAL CHARACTERISTICS OF PERSIMMON PUREE AND ITS UTILIZATION IN CUPCAKE
}

\author{
Dina A. Abdallah", M.R. Abd El-Mageed, H.A. Siliha and M.A. Rabie \\ Food Sci. Dept., Fac. Agric., Zagazig Univ., Egypt
}

Received: 15/10/2017 ; Accepted: 29/10/2017

\begin{abstract}
This study was carried out to investigate the chemical composition, antioxidant activity and phenolic compounds of persimmon puree and evaluate the impact of utilizing persimmon puree on some chemical, physical and organoleptic properties of cupcake. Persimmon puree was added to cupcake at a ratio of $33.3,50,66.6$ and $83.3 \%$. Results showed that persimmon puree contained $20 \%$ total soluble solids, $73.59 \%$ moisture, $32.5 \mathrm{mg} / 100 \mathrm{~g}$ vitamin C, $416.5 \mathrm{mg} / 100 \mathrm{~g}$ carotenoids. The major polyphenols identified in persimmon puree (in ppm) were Pyrogallol (183.40), Catechol (8.34), Ellagic (6.66), Epicatechein (6.56), Benzoic (5.05), Caffeine (4.93), Caffeic acid (4.37), Chlorogenic acid (4.32), Vanillic acid (2.88), Catechein (2.77), P. Hydroxy-benzoic acid (2.61), Ferulic acid (2.05), Salycilic (2.05), P.coumaric acid (1.32), Protocatchuic acid (1.11), Alpha-coumaric (0.99), Iso ferulic (0.73), Coumarin (0.69), Gallic (0.59), Reversetrol 0.51, 4-Amino benzoic( 0.48), 3-OH-Tyrosol (0.33), 3-4-5-Methoxy-Cinnamie (0.29) and Cinnamic (0.19). The major flavonoids detected in persimmon puree (in ppm) were Hisperidin (2.698), Rutin (0.104), Quercetrin (0.816), Luteolin (0.559), Narengin (0.534), Hispertin (0.057), Rosmarinic (0.047), Quercetin (0.026), 7-OH-ydroxy flavone (0.012), Kampferol (0.007), and Apegnin (0.007). Addition of persimmon puree to cupcake affected the organoleptic properties of cupcake samples. Cupcake containing $33.3 \%$ persimmon puree had the highest score for physical and organoleptic properties compared to control and other treatments. Therefore this treatment was analyzed for total polyphenol content, antioxidants activity, physical and sensory properties. Results showed that persimmon puree cupcake had higher contents of total phenolic, vitamin $\mathrm{c}$ and antioxidant activity than control sample. Moreover, persimmon puree cupcake had higher scores for the organoleptic properties than control sample. Based on the previous results, it can be concluded that utilization of persimmon puree in cupcake manufacture at a ratio of $33.3 \%$ can improve the chemical, physical and organoleptic characteristics as well as antioxidant activity of cupcake.
\end{abstract}

Key word: Persimmon puree, cupcake, chemical composition, antioxidants, polyphenols, flavonoids, cupcake properties.

\section{INTRODUCTION}

Persimmon fruit (Diospyros kaki L.) belongs to the Ebenaceae family. In Egypt the cultivated area with persimmon is about 11570 faddans producing about 34430 tons (EEAR, 2015). It is cultivated worldwide with $90 \%$ of the production is provided by china, Japan and Korea (Denev and Yordanov, 2013). Large numbers of cultivars are commercially produced. The major differences between cultivars are the presence of

\footnotetext{
* Corresponding author: Tel. : +201274532424
}

E-mail address: dina.ali20172019@gmail.com stringency and seeds (East et al., 2011). Astringent cultivars require ripening (until they are soft) before being consumed, whereas nonastringent cultivars can be consumed when either a crisp apple like texture are soft peak like texture (Seong and Han, 1999; Bubba et al., 2009). The persimmon is considered as a climacteric fruit, having the ability to continue ripen subsequent to harvest.

Nowadays it is considered as a popular fruit due to its unique flavour and taste and its 
significant health benefits. Persimmon could be consumed as fresh or processed products. Its various products can be obtained from persimmon such as dried fruits, jams, juices, jelly, candy, wine, vinegar and it can be used in the ice- cream and toffee manufacturing (Gao et al., 2010; East et al., 2011; Karaman et al., 2014; Jiménez-sánchez et al., 2015; Oksuz et al., 2015). The contents of primary and secondary metabolites such as sugars, organic acids, carotenoids and polyphenols are vary significantly in different cultivars of persimmon (Veberic et al., 2010). Flavour and sensory characteristics, but also to the nutritional properties and beneficial health effects of persimmon fruit related to the chemical composition of persimmon fruit (Veberic et al., 2010). It is commonly known that the contents of individual sugars as well as the sugar/acid ratio directly correlate with the sweetness of persimmon fruit (Schwieterman et al., 2014). The colour of persimmon fruit in different cultivars varies from yellow and orange to deep red which resulted from the different contents of carotenoids (Zhou et al., 2011). Persimmon fruits with high concentration of carotenoids and polyphenols have potential effects on preventing cardiovascular diseases (George Redpath, 2008). Thabit (2010) showed that the moisture content in persimmon fruits ranged from 72.05 to $82 \%$ (on fresh weight basis). Ito (2000) reported that the concentration of total soluble solids ranged from 18.0 to $20.8 \%$ in astringent persimmon fruits and $16.2 \%$ in non-astringent persimmon fruits. Lyon et al. (2008) found that the $\mathrm{pH}$ value of fuyu persimmon cultivars was 6.06 at harvest, while it was 5.97 for fruit stored at $18^{\circ} \mathrm{C}$ for two weeks. Attia et al. (2013) found that total acidity of persimmon fruit ranged between 0.14 and $0.30 \%$. Denev and Yordanov (2013) found that commercial harvest stage, total sugar content varied between 9.6 and $14.4 \mathrm{~g} / 100 \mathrm{~g}$ and increased slightly to $11.5-16.5 \mathrm{~g} / 100 \mathrm{~g}$ of the maturation. Glucose and fructose were found to be predominant sugars. Gorinstein et al. (2011) reported that ascorbic acid content in persimmon fruit ranged between 12.6 to $50 \mathrm{mg} / 100 \mathrm{~g}$ (on fresh weight basis). Forbus et al. (2011) showed that total carotenoids ranged from 212.0-265.6 $\mathrm{mg} / 100 \mathrm{~g}$ and can be as higher as 1400-2330 $\mathrm{mg} / 100 \mathrm{~g}$ (Thabit, 2010). Turk (2012) found that alcohol insoluble solids ranged between 1.22 and $4.33 \%$. Celik and Ercisli (2008) showed that the colour of persimmon puree were $\mathrm{L}=33.2$ to 89.3 $a=7.67$ to 18.1 and $b=20.3$ to 60.5 . The variation between chemical and physical properties may be due to variation in variety, climatic conditions and harvesting season. Gorinstein et al. (2000) determined $\mathrm{Na}$ (4.94), K (198.2), Fe (99.2), Mn (101.2), $\mathrm{Cu}$ (9.3), Zn (13.9) mg/100 g in fresh persimmon. Ksouri et al. (2009) and Veberic et al. (2010) reported that persimmon contained Rutin, Quercetrin, Quercetin and Hesperidin which valued as much as 0.066 or $98.34,0.645$ or $63.20,0.224$ or $23.82,15.94 \mathrm{mg} / \mathrm{kg}$, respectively. Oksuz et al. (2015) found that total phenolic content was $428.62 \mathrm{mg}$, Gallic acid/100 mg (dry weight). Suzuki et al. (2015) reported that persimmon has different total phenolic compound depending on cultivars, parts and solvents extraction. The fruit is a good source of carbohydrates, vitamin $\mathrm{A}$, vitamin $\mathrm{C}$, minerals, dietary fiber, tannins, polyphenols, flavonoids and carotenoids (Butt et al., 2015).

The aim of the present investigation was to characterize the physical, chemical and bioactive compounds of persimmon puree and evaluate the effect of utilizing persimmon puree on some quality parameters of cupcake.

\section{MATERIALS AND METHODS}

\section{Materials}

\section{Plant material and chemicals}

Fresh persimmon fruits were purchased from the local market in Zagazig city, Sharkia Governorate, Egypt. Wheat flour (72\% extraction) was obtained from Cairo East Co. of Milling, Cairo, Egypt. Baking ingredients such as sugar (sucrose; a commercial grade), salt, botteled water, shortening, fresh whole egg, baking powder and vanilla were obtained from local supermarket in Zagazig City, Sharkia Governorate, Egypt. Acetic acid, methanol, and acetonitrile used in the HPLC analysis were purchased from Merck (Darmstadt, Germany). Standard phenolic and flavonoid compounds and Folin-Ciocalteu's phenol reagent were obtained from Sigma Chemical Co. 


\section{Methods}

\section{Preparation of persimmon puree}

Fresh persimmon fruits were washed and peeled. Fruits were cut into slices and blended in a mixer (Panasonic MK-H4-W, Malaysia). The puree was put in double jacket and heated at $60^{\circ} \mathrm{C}$ for $20 \mathrm{~min}$. The resultant puree was cooled in water bath (Matsuo et al., 2004).

\section{Preparation of cupcakes}

Cupcake was prepared according to the method outlined by AACC (2002). The shortening $(120 \mathrm{~g})$ was melted and mixed with sugar $(225 \mathrm{~g})$ and salt (5 g) using electric mixer (Panasonic MK-H4-W, Malaysia). The whole egg (175 g) was mixed with vanillia (5 g) and whipped until smooth like-cream texture was formed. Wheat flour $(250 \mathrm{~g})$ was mixed with baking powder $(10.5 \mathrm{~g})$ and added gradually together with water $(250 \mathrm{ml})$ to the whipped egg mixture. This mixture was beaten gently until homogenous dough is formed using hand mixer. Persimmon puree was added as a substitute of the sugar solution in a ratio of $33.3 \%, 50 \%, 66.6 \%$ and $83.3 \%$ as indicated in Table 1. After getting appropriate texture, the dough was poured into paper cups mounted in cupcake tray and backed at $180^{\circ} \mathrm{C} \pm 5^{\circ} \mathrm{C}$ for $30-35 \mathrm{~min}$. The baked cupcakes were allowed to cool down at room temperature, packed into aluminum foil and stored at room temperature.

\section{Assessments}

\section{Chemical composition}

Total soluble solids, total sugars, reducing sugars, non-reducing sugars, moisture, acidity, $\mathrm{pH}$, vitamin $\mathrm{C}$, alcohol insoluble solids, carotenoids and minerals of persimmon puree were determined according to AOAC (2005). Carbohydrates content was calculated by difference according to FAO (2003).

\section{Determination of specific volume of cupcake}

The weight $(\mathrm{g})$ of baked cupcakes was determined individually within one hour after baking and the average was calculated. The volume $\left(\mathrm{cm}^{3}\right)$ of different substituted cupcakes was determined by rape seeds displacement method according to AACC (2002). Specific volume $\left(\mathrm{cm}^{3} / \mathrm{g}\right)$ of cupcake was calculated by dividing cupcake volume by cupcake weight.

\section{Preparation of methanol extract}

Persimmon fruits were subjected to simple process of solid and liquid separation (Lu et al., 2010). After the core of the persimmon fruit was removed, the remaining materials were centrifuged at $5,000 \mathrm{rpm}$ for $10 \mathrm{~min}$. The supernatant decanted and put in round flask and freeze-dried at $-70^{\circ} \mathrm{C}$.

\section{Preparation of the extracts for antioxidant activities}

The freeze-dried material was extracted with methanol for two days at room temperature. Antioxidant activity, total phenolic content and total flavonoid content of methanol extract were determined. Sugar analysis of persimmon was carried out according to the method of Lu et al. (2010).

\section{DPPH radical scavenging activity}

The DPPH radical scavenging activities in the methanol extracts of all samples were measured by the method described by Lee et al. (2006) with a slight modification. Briefly, sample extracts $(0.1 \mathrm{ml})$ at various concentrations were added to both $0.49 \mathrm{ml}$ of methanol and $0.39 \mathrm{ml}$ of a DPPH methanolic solution $(1 \mathrm{mM})$. The mixtures were vigorously vortexed and incubated for $30 \mathrm{~min}$ at room temperature in the dark. The absorbance of mixtures was determined by using a Beckman DU650 Spectrophotometer (Beckman Coulter, Fullerton, CA, USA). BHT was used as the reference. The scavenging activity was expressed as a percentage using the following formula:

DPPH radical scavenging activity (\%) = (1-absorbance of sample/absorbance control) $\times 100$

\section{Determination of total phenolic content}

The total phenolic content of the methanolic extract was determined using the FolinCiocalteau method (Meda et al., 2005). Briefly, each sample $(500 \mu \mathrm{l})$ was added to $250 \mu \mathrm{l} 2 \mathrm{~N}$ Folin-Ciocalteau reagent. After $5 \mathrm{~min}, 500 \mu \mathrm{l}$ of $7 \% \mathrm{Na}_{2} \mathrm{Co}_{3}$ solution was added with mixing. After $1 \mathrm{hr}$ at room temperature, the absorbance at $750 \mathrm{~nm}$ (Beckman Coulter DU650) was measured. The standard curve for total phenolic was made using gallic acid solutions $(0,50,100$, 250 , and $500 \mathrm{mg} / \mathrm{l})$ with the same procedure as mentioned above. The results were expressed as $\mathrm{mg}$ gallic acid equivalents (GAE/g extract). 
Abdallah, et al.

Table 1. Substitution of sugar solution by different added levels of persimmon puree

\begin{tabular}{lccc}
\hline Sample & $\begin{array}{c}\text { Persimmon puree } \\
(\mathrm{g})\end{array}$ & $\begin{array}{c}\text { Sugar solution } \\
(\mathbf{g})\end{array}$ & $\begin{array}{c}\text { Substitution of sugar solution by } \\
\text { persimmon puree (\%) }\end{array}$ \\
\hline Control & - & 250 & - \\
T1 & 100 & 150 & $33.30 \%$ \\
T2 & 150 & 100 & $50.00 \%$ \\
T3 & 200 & 50 & $66.60 \%$ \\
T4 & 250 & - & $83.30 \%$ \\
\hline
\end{tabular}

$\mathrm{T} 1=$ cupcake containing $33.3 \%$ persimmon puree, $\mathrm{T} 2=$ cupcake containing $50 \%$ persimmon puree, $\mathrm{T} 3=$ cupcake containing $66.6 \%$ persimmon puree and $\mathrm{T} 4=$ cupcake containing $83.3 \%$ persimmon puree.

\section{Determination of total flavonoid contents}

The total flavonoid content was determined using a modified colorimetric method (Abeysinghe et al., 2007). The diluted extract $(1 \mathrm{ml})$ was added to a test tube containing $7 \mathrm{ml}$ of methanol after addition of $2 \mathrm{ml}$ of $90 \%$ diethylene glycol. The reaction mixture was initiated by adding $0.1 \mathrm{ml}$ of $4 \mathrm{M}$ sodium hydroxide. After heating for $30 \mathrm{~min}$ at $50^{\circ} \mathrm{C}$, the reaction mixture was incubated at room temperature for $30 \mathrm{~min}$. The absorbance of the solution was measured at $420 \mathrm{~nm}$ (Beckman Coulter DU650). Total flavonoid content was determined using a standard curve of rutin $(0,10$, 25 , and $50 \mathrm{mg} / \mathrm{l}$ ) and then expressed as $\mathrm{mg}$ rutin equivalents ( $\mathrm{RE} / \mathrm{g}$ extract).

Identification and quantification of phenolic and flavonoid of the persimmon puree compounds by HPLC

The phenolic and flavonoid compounds of the persimmon puree samples were identified according to the method described by Goupy et al. (1999) and Mattila et al. (2000) by using HPLC instrument (Hewlett Packard series 1050, USA) composed of column C18 hypersil BDS with particle size $1 \mathrm{~mm}$. The separation was carried out by gradient duties using methanol and acetonitrile as a mobile phase $(50: 50 \mathrm{~V} / \mathrm{V})$. The flow rate was $1 \mathrm{ml} / \mathrm{min}$. Quantification was carried out using standards of phenolic and flavonoid compounds. This assay was conducting in Agricultural Res. Center Laboratory, Cairo, Egypt.

\section{Colour Measurement}

Colour attributes $\left(\mathrm{L}^{*}, \mathrm{a}^{*}\right.$, and $\left.\mathrm{b}^{*}\right)$ of Persimmon purees cupcake were measured according to See et al. (2007) using hunter Lab colour flex EZ spectrophotometer. $\mathrm{L}^{*}$ value defines lightness, $\mathrm{a}^{*}$ value denotes the red/green colour and $b^{*}$ value the yellow/blue colour.

\section{Organoleptic Properties}

The organoleptic properties of cupcakes were 10 panelists according to AACC (2000). Cupcake samples were left to cool at room temperature for $1 \mathrm{hr}$., after baking, then cut with a sharp knife and subjected to panel test. The score was as follows 10: flavour, 10: texture, 10: colour, 10: taste, and 10: overall acceptability.

\section{Statistical Analysis}

All data were statistically analyzed using the general linear models procedure of the statistical analysis system SAS (1998). Significances of differences were defined at $p<0.05$.All experiments as well as related analysis results were repeated three times and all obtained data are expressed as an average .In addition, this statistical analysis was used for sensory evaluation of persimmon cupcake.

\section{RESULTS AND DISCUSSION}

\section{Chemical Composition of Persimmon Puree}

The chemical composition of persimmon puree was determined and the obtained results are presented in Table 2. Total soluble solids content of the persimmon puree was $20.12^{\circ}$ brix. This is in agreement with that obtained by Attia et al. (2013) who found that total soluble solids content of persimmon cultivars ranged from 17.8 
Table 2. Chemical and physical characteristics of persimmon puree (fresh weight basis)

\begin{tabular}{ll}
\hline Properties & Persimmon puree \\
\hline Total soluble solids & $20.12^{\circ}$ brix \\
Total sugars & $15.50 \%$ \\
Reducing sugars & $13.80 \%$ \\
Non - Reducing sugars & $1.70 \%$ \\
Moisture & $73.59 \%$ \\
Titratable acidity (as citric acid) & $0.15 \%$ \\
pH & 5.82 \\
Vitamin C & $32.50 \mathrm{mg} / 100 \mathrm{~g}$ \\
Alcohol insoluble solids & $1.79 \%$ \\
Carotenoids & $416.50 \mathrm{mg} / 100 \mathrm{~g}$ \\
Colour (Hunter values) & $\mathrm{L}^{*}=45.33$ \\
& $\mathrm{a}^{*}=17.35$ \\
\hline
\end{tabular}

to $22.6 \%$ depending on the variety. Total, reducing and non-reducing sugars content of persimmon puree were $15.5 \%, 13.8 \%$ and $1.7 \%$, respectively. These results are in agreement with those obtained by Denev and Yordanov (2013) who found that commercial harvest stage; total sugar content varied in the range of 9.6 and 14.4 $\mathrm{g} / 100 \mathrm{~g}$ and increased slightly to $11.5-16.5$ $\mathrm{g} / 100 \mathrm{~g}$ at the maturation. Glucose and fructose were found to be the predominant sugars.

Moisture content of persimmon puree was $73.59 \%$ (Table 2). Titratable acidity determined as citric acid was $0.15 \%$. Similar values has been reported by Attia et al. (2013) who found that total acidity of persimmon fruit ranged between 0.14 and $0.30 \%$.

Concerning $\mathrm{pH}$ value of persimmon puree from the results presented in Table 2, the $\mathrm{pH}$ value was found to be 5.82. This is in agreement with the result obtained by Homnava et al. (2014) who stated that $\mathrm{pH}$ value of different varieties of fresh persimmon was in the range of 5.5 to 6.08 .

It is well known that the predomination vitamin in persimmon fruit is vitamin $\mathrm{C}$, existing in two vitamins- ascorbic acid and dehydro- $\mathrm{L}$ ascorbic acid. Giordani et al. (2011) stated that
100-150 g of fresh persimmon supplies the recommended daily amount. Vitamin C content in persimmon puree was $32.5 \mathrm{mg} / 100 \mathrm{~g}$. This is in accordance with the results obtained by Gorinstein et al. (2011) who found that ascorbic acid content in persimmon fruit ranged between 12.6 and $50 \mathrm{mg} / 100 \mathrm{~g}$ and lower than those reported by Thabit (2010) who found that ascorbic acid content was ranged from 55.59 to $59.71 \mathrm{mg} / 100 \mathrm{~g}$ in flesh of persimmon cultivars.

Alcohol insoluble solids content in persimmon puree presented in Table 2 is $1.79 \%$. Turk (2012) found that alcohol insoluble solids ranged between 1.22 and $4.33 \%$.

Carotenoids give the fruit its characteristic reddish- orange colour consisting of $\beta$ - carotene, $\gamma$-carotene and $\beta$-cryptoxanthin (Veberic et al., 2010). Carotenoids content in persimmon puree were $416.5 \mathrm{mg} / 100 \mathrm{~g}$. Lower values were reported by Forbus et al. (2011) who showed that total carotenoids ranged from 212.0 to 265.6 $\mathrm{mg} / 100 \mathrm{~g}$., whereas higher concentration (1400$2330 \mathrm{mg} / 100 \mathrm{~g}$ ) was reported by Thabit (2010).

Results presented in Table 2 show that the colour attributes of persimmon puree were $\mathrm{L}^{*}=$ $45.33 \mathrm{a}^{*}=17.35$ and $\mathrm{b}^{*}=25.19$. These results are 
in agreement with those reported by Celik and Ercisli (2008) who showed that the colour of persimmon puree were $L^{*}=33.2$ to $89.3 \mathrm{a}^{*}=7.67$ to 18.1 and $b^{*}=20.3$ to 60.5 depending on the variety of persimmon.

\section{Phenolic compounds in persimmon puree}

Suzuki et al. (2015) indicated that persimmon has different total phenolic compound depending on cultivars, parts, and solvents extraction. Sattar et al. (2013) reported that the amounts of phenolic compounds in persimmon extracts from 5 cultivated genotypes were different, because phenolic content of plants depends up on both quantitatively and qualitatively on their genetic information. The different of phenolic compounds may be affected by a variety and environments contents including light, temperature, humidity, drought, and agronomic conditions factors, in the different harvest regions. Results presented in Table 3 show that 24 phenolic compounds were identified from persimmon puree. The major identified and quantified phenolic compounds in persimmon puree were in decreasing order (as follow $\mathrm{mg} / \mathrm{kg}$ puree) Pyrogallol (183.40), Catechol (8.34), Ellagic (6.66), Epicatechein (6.56), Benzoic (5.05), Caffeine (4.93), Caffeic acid (4.37), Chlorogenic acid (4.32). Other phenolic compound were found with low concentrations as shown in Table 3. It is worthwhile stating that Pyrogallol which was identified as the predominant phenolic compound in persimmon puree was not identified by several authors in persimmon fruit (Hudina et al., 2008; Vebric et al., 2010). Total phenolic compounds in persimmon fruit (without skin) has been reported by Gorinstein et al. (2015) for Triumph variety $(115 \mathrm{mg} / 100 \mathrm{~g})$ and for Fuio variety $(121 \mathrm{mg} / 100 \mathrm{~g})$. Oksuz et al. (2015) found that total phenolic content was $428.62 \mathrm{mg}$ gallic acid/100 mmol dry weight basis).

\section{Flavonoid compounds in persimmon puree}

Results presented in Table 4 show the content of flavonoid compounds in persimmon puree. Flavonoids, including flavanones, flavones, flavanols and anthocyanins are the most important aromatic secondary metabolites and their consumption has been linked to the protection against cancer, heart disease and oxidants (Hertog et al., 2012). The concentration of Rutin, Quercetrin, Quercetin, Hisperidin were
$0.104, \quad 0.816, \quad 0.026$ and $2.698 \mathrm{mg} / \mathrm{kg}$, respectively. These results were higher than those obtained by Ksouri et al. (2009) or Veberic et al. (2010) who reported that Rutin, Quercetrin, Quercetin and Hisperidin were 0.066 or 98.34 , 0.645 or $63.20,0.224$ or $23.82,15.94 \mathrm{mg} / \mathrm{kg}$, respectively. Concerning the results from Table 4; Luteolin, Rosmarinic, Narengin, Hispertin, Kampferol, Apegnin, 7-Hydroxy flavone were $0.559,0.047,0.534,0.057,0.007,0.007$, and $0.012 \mathrm{mg} / \mathrm{kg}$., respectively.

\section{The Effect of Persimmon Puree on Physical and Sensory Properties of Cupcake}

\section{Specific volume of cupcake}

Cupcakes were prepared by adding different quantities of persimmon puree $(33.3,50,66.6$ and $83.3 \%$ ) in order to improve the nutritional and antioxidants activity of cupcakes. Table 5 shows the weight, volume and specific volume of resultant cupcakes. The volume of cupcake containing $33.3 \%$ persimmon puree was found to be the highest among the other cupcakes. The specific volume $\left(\mathrm{cm}^{3} / \mathrm{g}\right)$ of control cupcake was 1.17 which was increased by $138 \%$ as a result of addition $33.3 \%$ persimmon puree. Addition of higher quantity of persimmon caused a pronounced reduction in specific volume and this may due to the compactnent of the texture as a result of addition of high quantity of persimmon puree.

From the previous results it could be concluded that cupcake containing $33.3 \%$ persimmon puree (T1) had the highest score of physical than control and other treatments. Therefore, this treatment was further analyzed in respect to total phenolic content, vitamin $\mathrm{C}$ content, antioxidants activity, physical and sensory properties and was compared to control. Table 6 shows that $\mathrm{T} 1$ has the maximum value of taste compared to the control which had the minimum value of taste, while $\mathrm{T} 3$ and $\mathrm{T} 4$ had the lowest values than T2. Concerning to flavour results in Table 6 show that $\mathrm{T} 1$ contained the highest value of flavour compared to the control, while $\mathrm{T} 3$ and T4 had low value than T2. On the other hand, texture in T1 had the highest value compare to the control while T3and T4 had low value than T2. Results in Table 6 shows that $\mathrm{T} 1$ had the highest value for colour compared to the control while $\mathrm{T} 2$ and $\mathrm{T} 4$ had low value than T3. On the other hand, overall 
Table 3. Identification of phenolic compounds in persimmon puree $(\mathrm{mg} / \mathrm{kg})$ by HPLC

\begin{tabular}{lc}
\hline Phenolic compound & Concentration \\
\hline Pyrogallol & 183.40 \\
Catechol & 8.34 \\
Ellagic acid & 6.66 \\
Epicatechin & 6.56 \\
Benzoic acid & 5.05 \\
Caffeine & 4.93 \\
Caffeic acid & 4.37 \\
Chlorogenic acid & 4.32 \\
Vanillic acid & 2.88 \\
Catechin & 2.77 \\
P. Hydroxy-benzoic acid & 2.61 \\
Ferulic acid & 2.05 \\
Salycilic acid & 2.05 \\
P. coumaric acid & 1.32 \\
Protocatchuic acid & 1.11 \\
Alpha-coumaric acid & 0.99 \\
Iso ferulic acid & 0.73 \\
Coumarin & 0.69 \\
Gallic acid & 0.59 \\
Reversetrol & 0.51 \\
4-Amino benzoic acid & 0.48 \\
3-hydroxytyrosol & 0.33 \\
3-4-5-trimethoxycinnamie acid & 0.29 \\
Cinnamic acid & 0.19 \\
Total phenolic compounds & 241.17 \\
\hline
\end{tabular}

Table 4. Identification of flavonoid compounds in persimmon puree $(\mathrm{mg} / \mathrm{kg})$ by HPLC

\begin{tabular}{lc}
\hline Flavonoid compound & Concentration $\mathbf{( m g / \mathbf { k g } )}$ \\
\hline Hisperidin & 2.698 \\
Rutin & 0.104 \\
Quercetrin & 0.816 \\
Luteolin & 0.559 \\
Narengin & 0.534 \\
Hispertin & 0.057 \\
Rosmarinic & 0.047 \\
Quercetin & 0.026 \\
7-OH-ydroxy flavone & 0.012 \\
Apegnin & 0.007 \\
Kampferol & 0.007 \\
Total Flavonoid content & 4.867 \\
\hline
\end{tabular}


Abdallah, et al.

Table 5. Effect of adding persimmon puree on physical properties of cupcake

\begin{tabular}{lccccc}
\hline Sample & \multicolumn{5}{c}{ Treatment } \\
\cline { 2 - 6 } & $\mathbf{C}$ & T1 & T2 & T3 & T4 \\
\hline Weight $(\mathbf{g})$ & 24 & 25 & 27 & 30 & 33 \\
Volume $\left(\mathbf{c m}^{\mathbf{3}}\right)$ & 28 & 69.7 & 61.4 & 49.7 & 14.7 \\
Specific volume $\left(\mathbf{c m}^{\mathbf{3}} / \mathbf{g}\right)$ & 1.17 & 2.79 & 2.27 & 1.66 & 0.45 \\
\hline C=cic
\end{tabular}

$\mathrm{C}=$ control cupcake

$\mathrm{T} 1=$ cupcake containing $33.3 \%$ persimmon puree. $\quad \mathrm{T} 2=$ cupcake containing $50 \%$ persimmon puree $\mathrm{T} 3=$ cupcake containing $66.6 \%$ persimmon puree $\quad \mathrm{T} 4=$ cupcake containing $83.3 \%$ persimmon puree

Table 6. Effect of adding persimmon puree on sensory properties of cupcake

\begin{tabular}{lccccc}
\hline Sample & $\begin{array}{c}\text { Taste } \\
(\mathbf{1 0})\end{array}$ & $\begin{array}{c}\text { Flavour } \\
(\mathbf{1 0})\end{array}$ & $\begin{array}{c}\text { Texture } \\
(\mathbf{1 0 )}\end{array}$ & $\begin{array}{c}\text { Colour } \\
(\mathbf{1 0})\end{array}$ & $\begin{array}{c}\text { Overall acceptable } \\
(\mathbf{1 0 )}\end{array}$ \\
\hline C & 7.89 & 7.28 & 7.57 & 7.39 & 7.53 \\
T1 & 8.28 & 7.78 & 8.46 & 8.78 & 8.33 \\
T2 & 6.85 & 6.92 & 6.42 & 6.64 & 6.71 \\
T3 & 6.60 & 6.28 & 6.10 & 6.89 & 6.47 \\
T4 & 6.53 & 5.92 & 6.07 & 6.10 & 6.16 \\
\hline C $=$ &
\end{tabular}

$\mathrm{C}=$ control cupcake

$\mathrm{T} 1$ = cupcake containing $33.3 \%$ persimmon puree $\quad \mathrm{T} 2=$ cupcake containing $50 \%$ persimmon puree

$\mathrm{T} 3=$ cupcake containing $66.6 \%$ persimmon puree $\quad \mathrm{T} 4=$ cupcake containing $83.3 \%$ persimmon puree

acceptablity in $\mathrm{T} 1$ had the highest value compared to the control while $\mathrm{T} 3$ and $\mathrm{T} 4$ had low value than T2. Moreover, sensory analysis of cupcake showed that taste, flavour, texture, color and overall acceptability scores of cupcake containing $33.3 \%$ persimmon puree were perceived by the panalists as the most acceptable one (Table 6). Therefore, treatment $\mathrm{T} 1$ was selected to carry on further.

Total phenolics content, vitamin $\mathrm{C}$ and antioxidants activity of persimmon cupcake

Table 7 shows that total polyphenols content of $33.3 \%$ persimmon cupcake was increased by $220 \%$ compared to control cupcake. Similarly, vitamin $\mathrm{C}$ content of persimmon cupcake was increased by $7766 \%$ compared to control cupcake. Phenolic compounds and vitamin $\mathrm{C}$ constitute some of the major compounds acting as free radical scavengers.

Antioxidant activity measured by DPPH is presented in Table 7. Antioxidant activity of persimmon cupcake was found to be higher than that of control cupcake. At $100 \mathrm{ppm} \mathrm{DPPH}$, the antioxidant activity increased from $35.42 \%$ in the control cupcake to $54.48 \%$ in the persimmon cupcake. Similarly at $200 \mathrm{ppm}$ DPPH the antioxidant activity increased from $42.32 \%$ of the control cupcake to $62.57 \%$ in the persimmon cupcake. The respective values at $300 \mathrm{ppm}$ DPPH were $48.36 \%$ and $68.99 \%$. The results clearly showed that, addition of persimmon puree to cupcake recipe improved its contents of polyphenols and vitamin $\mathrm{C}$ and improved the antioxidant activity to a prounounced extent.

\section{Some physical characteristics of persimmon cupcake}

Results in Table 8 indicate that the volume and specific volume of persimmon cupcake were higher than control cupcake. Moreover, the colour parameters show lightness $\left(\mathrm{L}^{*}\right)$ of the crust was decreased as a result of persimmon addition to cupcake recipe. Redness $\left(\mathrm{a}^{*}\right)$ and yellowness $\left(b^{*}\right)$ of persimmon cupcake were lower than the control cupcake. The control cupcake was darker than the persimmon cupcake and this phenomenon may due to the browning reactions such as maillard reaction which could take place during the baking of the cupcake. As for the colour parameters of the crumb, results in Table 8 indicated that $\mathrm{L}^{*}$ and $\mathrm{b}^{*}$ were decreased whereas $a^{*}$ value was increased showing that move redish colour is observed in persimmon cupcake.

\section{Sensory evaluation of persimmon cupcake}

Results in Table 9 shows that, the sensory scores of persimmon puree cupcake were higher than control cupcake, indicating that palatability of persimmon cupcake was higher than control cupcake. 
Table 7. Total polyphenols, vitamin $\mathrm{C}$ and antioxidants activity of persimmon cupcake

\begin{tabular}{lcc}
\hline Antioxidants constituents & Control & Persimmon cupcake (33.3\%) \\
\hline Total polyphenols (mg/g) & 0.263 & 0.843 \\
Vitamin C (mg/100 g) & 0.003 & 0.236 \\
Antioxidant activity at DPPH (100 ppm) & 35.42 & 54.48 \\
Antioxidant activity at DPPH (200 ppm) & 42.32 & 62.57 \\
Antioxidant activity at DPPH (300 $\mathbf{~ p p m ) ~}$ & 48.36 & 68.99 \\
\hline
\end{tabular}

Table 8. Physical characteristics of persimmon cupcake

\begin{tabular}{lcc}
\hline & \multicolumn{2}{c}{ Treatment } \\
\cline { 2 - 3 } & Control & Persimmon cupcake \\
\hline Weight (g) & 24 & 25 \\
Volume (cm $\left.{ }^{3}\right)$ & 35 & 77 \\
Specific volume $\left(\mathbf{c m}^{3} / \mathbf{g}\right)$ & 1.4 & 3.08 \\
Crust colour & & \\
$\mathbf{L}^{*}$ & 47.51 & 31.94 \\
$\mathbf{a}^{*}$ & 10.15 & 8.24 \\
$\mathbf{b}^{*}$ & 24.05 & 13.90 \\
Crumb colour $^{*}$ & & \\
$\mathbf{L}^{*}$ & 63.95 & 35.94 \\
$\mathbf{a}^{*}$ & 2.02 & 5.06 \\
$\mathbf{b}^{*}$ & 22.00 & 11.38 \\
\hline
\end{tabular}

Table 9. Sensory evaluation of persimmon cupcake

\begin{tabular}{lccccc}
\hline Treatment & $\begin{array}{c}\text { Taste } \\
\mathbf{( 1 0 )}\end{array}$ & $\begin{array}{c}\text { Flavour } \\
(\mathbf{1 0 )}\end{array}$ & $\begin{array}{c}\text { Texture } \\
(\mathbf{1 0}) \text { (Sponge) }\end{array}$ & $\begin{array}{c}\text { Colour } \\
(\mathbf{1 0})\end{array}$ & $\begin{array}{c}\text { Overall } \\
\text { acceptable (10) }\end{array}$ \\
\hline Control & $8.066^{\mathrm{bc}}$ & $7.605^{\mathrm{d}}$ & $7.813^{\mathrm{c}}$ & $7.714^{\mathrm{c}}$ & $7.613^{\mathrm{b}}$ \\
Persimmon cupcake with $\mathbf{3 3 . 3 \%}$ & $8.866^{\mathrm{a}}$ & $8.515^{\mathrm{a}}$ & $8.366^{\mathrm{a}}$ & $8.333^{\mathrm{a}}$ & $7.717^{\mathrm{a}}$ \\
\hline
\end{tabular}




\section{REFERENCES}

AACC (2000). Approved Methods of the American Association of Cereal Chemists. Ame. Assoc. Cereal Chem., St. Paul.

AACC (2002). Approved Methods of the American Association of Cereal Chemists. Ame. Assoc. Cereal Chem., St. Paul.

Abeysinghe, D.C., X. Li, C.D. Sun, W.S. Zhang, C.H. Zhou and K.S. Chen (2007). Bioactive compounds and antioxidant capacities in different edible tissues of citrus fruit of four species. Food Chem., 104: 1338-1344.

AOAC (2005). Official Methods of Analysis, $18^{\text {th }} \mathrm{Ed}$. The Assos. Official Analytical Chem., Washington, DC.

Attia, R.S., W.A. Amin and Y.G. Moharram (2013). Adaptability of persimmon fruits (Diospyros kaki L.) for preparation intermediate moisture products. Alex. J. Agric. Res., 43 (3) : 105-119.

Bubba, M.D., E. Giordani, L. Pippucci, A. Cincinelli, L. Checchini and P. Galvan (2009). Changes in tannins,ascorbic acid and sugar content in astringent persimmons during on-tree growth,ripening and in response to different postharvest treatments. J. Food compos. Anal., 22 : 668-677.

Butt, M.S., M.T. Sultan, M. Aziz, A. Naz, W. Ahmed, N. Kumar and M. Imran (2015). Persimmon (Diospyros kaki L.) fruit: hidden phytochemicals and health claims. EXCLI J., 14: 542-561.

Celik, A. and S. Ercisli (2008). Persimmon cv. Hachiya (Diospyros kaki Thunb.) fruit : some physical, chemical and nutritional properties. Int. J. Food Sci. Nutr., 59:599 -606.

Denev, P. and A. Yordanov (2013). Total polyphenol, proanthocyanidin and flavonoid content, carbohydrate composition and antioxidant activity of persimmon (Diospyros $k a k i$ L.) fruit in relation to cultivar and maturity stage. Bulgarian J. Agric. Sci., 19: (5): 981-988.

EEAR (2015). Egyptian Economic Agriculture report, $350-351$.

East, A.R., X.H. Tan and I. Suntudprom (2011). Predicting Persimmon Puree Color as a Result of Puree Strength Manipulation. ICEF11. Int. and Cong. on Eng. and Food Proc. Eng. a Change World Held in Atheros, Grace in May 22-26: 1-5.

FAO (2003). Food Energy-Methods of Analysis and Conversion Factors. Food and Nut. Paper, Rome, 77.

Forbus, W.S., J.A. Payne and S.D. Senteer (2011). Non-destructive evaluation of Japanese persimmon maturity by delayed light emission. J. Food Sci., 56 (4): 985-988.

Gao, H.., J. Yang, B. Liu and S. Fu (2010). Optimization of the prescription persimmon vinegar tea beverage by response surface methodology. Inf. Manag. and Eng. (ICIME), $2^{\text {nd }}$ IEEE Int. Conf., IEEE, 121-123.

George, A. and S. Redpath (2008). Health and medicinal benefits of persimmon fruit: A review. Adv. Hort. Sci., 22:244-249.

Giordani, E., S. Doumett, S. Nin and M. Del Bubba (2011). Selected primary and secondary metabolites in fresh persimmon (Diospyros kaki Thunb.): A review of analytical methods and current knowledge of fruit composition and health benefits. Food Res. Int., 44:1752-1767.

Gorinstein, S., H. Ieontowicz, M. Leontowicz, I. Jesion, J. Namiesnik and J. Orzewiecki (2011). Influence of two cultivars of persimmon on athrosclerosis indices in rats fed cholesterolcontaining diets: Invest. in vitro and in vivo. Nutr., 27 (7): 838-846.

Gorinstein, S., Z. Zachwieja, M. Folta, H. Barton, J. Piotrowicz, M. Zember, M. Weisz, S. Trakhtenbery and O. Martin-Belloso, (2015). Comparative content of dietary fiber, total phenolics and minerals in persimmon and apples. J. Agric. Food. Chem., 49: 952-957.

Gorinstein, S., G. Kulasek, E. Bartnikowska, M. Leontowicz, M.M. Zemser and M. Orawiee (2000). The effects of diets, supplemented with either whole persimmon or phenol-free persimmon, on rats fed cholesterol. Food Chem., $70: 303-308$. 
Goupy, P.; M. Hugues, P. Boivin and M.J. Amiot (1999). Antioxidant composition and activity of barley (Hordeum vulgare) and malt extracts and of isolated phenolic compounds. J. Sci. Food and Agric., 79 (12): 1625-1634 .

Hertog, M.G.L., P.C.H. Hollman and D.P. Venema (2012). Optimization of a quantitative HPLC determination of potentially anticarcinogenic flavonoids in vegetables and fruits. J. Agric. Food Chem., 40 : 1591-1598.

Homnava, A., J. Pyne, P. Koehler and R. Eitenmeller (2014). Pro-vitamin A and ascorbic acid content of Japanese and American persimmon. J. Food Quality, 13: 85-95.

Hudina, M., R. Liu, F. Veberic and M. Stampar (2008). Phenolic compounds in the fruit of different varieties of Chinese jujube (Ziziphus jujube Mill.) J. Hort. Sci. Biotechnol., 83: $305-308$.

Ito, S. (2000). The persimmon. In: The Biochemistry of Fruits and Thier Products (Ed. Ac Hulme) Acad. press, New York, 281-301.

Jiménez-Sánchez, C., J. Lozanosanchez, N. Marti, D. Saura, M. Valero, A. SeguraCarretero, and A. Fernandez-Gutierrez (2015). Characterization of polyphenols, sugars, and other polar compounds in persimmon juices produced under different technologies and their assessment in terms of compositional variations. Food. Chem., 182 : 282-291.

Karaman, S., O.S.Y. Toker, F. Uksel, M.C. Am, A. Kayacier and M. Dogan (2014). Physicochemical, bioactive, and sensory properties of persimmon-based ice cream: Technique for order preference by similarity to ideal solution to determine optimum concentration, J. Dairy Sci., 97 (1):97-110.

Ksouri, R., H. Falleh, W. Megdiche, N. Trabelsi, B. Mhamdi and K. Chaieb (2009). Antioxidant and antimicrobial activities of the edible medicinal halophyte (Tamarix gallica L.) and related polyphenolic constituents. Food and Chem. Toxicol., 47 (8): 2083-2091.

Lee, B.W., J.H. Lee, S.W. Gal, Y.H. Moon and K.H. Park (2006). Selective ABTS radical-scavenging activity of prenylated flavonoids from Cudrania tricuspidata. Bioscience, Biotechnol. and Iochem., 70 (2): 427-432.

Lu, Z., F. He, Y. Shi, M. Lu and L. Yu (2010). Fermentative product of $\mathrm{L}(+)$-lactic acid using hydrolyzed a corn starch, persimmon juice and wheat bran hydrolysate as nutrients. Bioresource Technol., 101(10): 3642-3648.

Lyon, B.G., S.D. Senter and J.A.Payne (2008). Quality characteristics of oriental persimmon (Diospyros kaki cv. Fuyu) grown in the south eastern United States. J. Food Sci., 57 (3): 693-695.

Matsuo, T., H. Shimozono, S. Too and S. Itos (2004). Alteration in properties of Kaki tannin during heat-browning and purification. Fac. Agric., Kagoshima Univ., Kagoshima 890 Japan. J. Japanese-Soc. for Hort. Sci., 59 (1): 157-161.

Mattila, P., J. Astola and J. Kumpulainen (2000). Determination of flavonoids in plant material by HPLC with diode-array and electro-array detections. J. Agric. and Food Chem., 48 (12): 5834-5841.

Meda, A., C.E. Lamien, M. Romito, J. Millogo and O.G. Nacoulma (2005). Determination of the total phenolic, flavonoid and proline contents in Burkina Fasan honey, as well as their radical scavenging activity. Food Chem., 91 (3): 571-577.

Oksuz, T., E. Surek, Z.T. Caba and D. Erdil (2015). Phenolic contents and antioxidant activities of persimmon and red beet jams produced by sucrose impregnation. Food Sci. and Technol., 3(1): 1-8.

SAS (1998). User's guide. 6.12 Ed., Statistical Analysis System Institute Inc. Cary NC 27511-8000, USA.

Sattar, A., N. Bibi and M. Chaudry (2013). Phenolic compounds in persimmon during maturation and on-tree ripening. Mol. Nutr. Food. Res., 36 (5): 466 - 472.

Schwieterman, M.L., T.A. Colquhoun, E.A. Jaworski, L.M. Bartoshuk, J.L. Gilbert, D.M. Tieman, A.Z. Odabasi, H.R. Moskowitz K.M. Folta and H.J. Klee (2014). Strawberry flavor: diverse chemical compositions, a 
seasonal influence, and effects on sensory perception. PLOS One, 9 (2): e88446.

See, E., A.N. Aziah and W. Wan Nadiah (2007). Physico-chemical and sensory evaluation of breads supplemented with pumpkin flour. ASEAN Food J., 14 (2): 123-30.

Seong, J.H. and J.P. Han (1999). The qualitative differences of persimmon tannin and the natural removal of astringency. Korean, J. Postharv. Sci.Technol., 6: 66-70.

Suzuki, T., S. Someya, F. Hu and M. Tanokura (2015). Comparative study of catechin compositions in five Japanese persimmons (Diospyros kaki L.). Food Chem., 93 (1): 149-152.

Thabit, M. (2010). Chemical, technological and microbiological studies on persimmon and avocado fruit. M.Sc. Thesis, Fac. Agric., Cairo Univ., Egypt.

Turk, R. (2012). The cold storage of persimmons (Diospyros kaki cv. fuyo) harvested at different maturities and the effect of different maturities and the effect of different $\mathrm{CO}_{2}$ applications on fruit ripening. Physiol. Basis. Post. Technol., 343 : 190-194.

Veberic, R., J. Jurhar, M. Mikulic-petkovsek, F. Stamper and V. Schmitzer (2010). Comparative study of primary and secondary metabolites in 11 cultivars of persimmon fruit (Diospyros kaki L.). Food Chem., 119 (2): 477-483.

Zhou, C., D. Zhao, Y.; Sheng, J. Tao and Y. Yang (2011). Carotenoids in fruits of different persimmon cultivars. Molecules, 16 (1): 624 636.

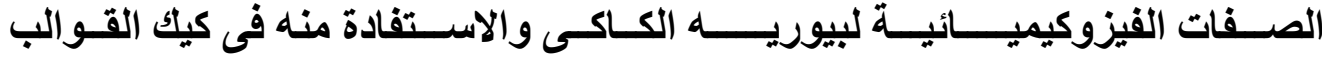

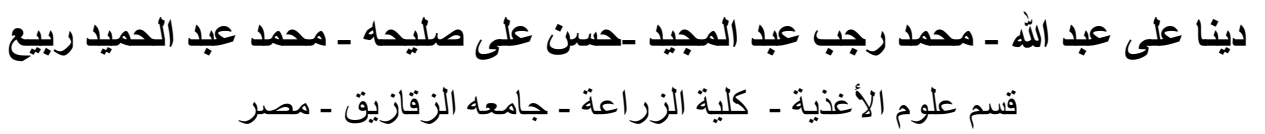

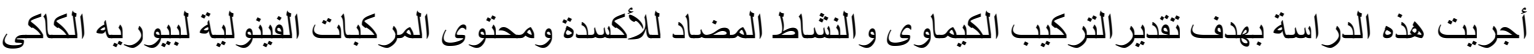

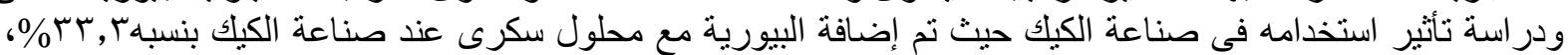

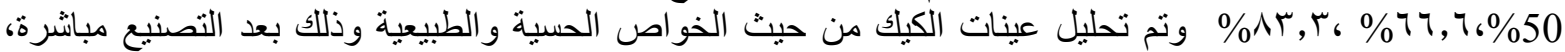

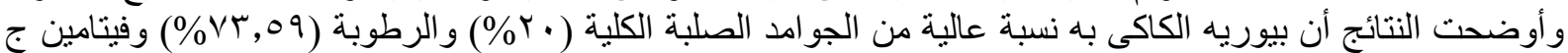

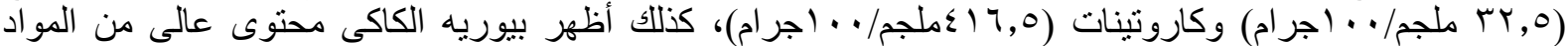

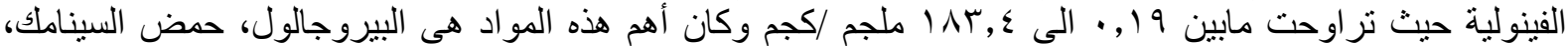

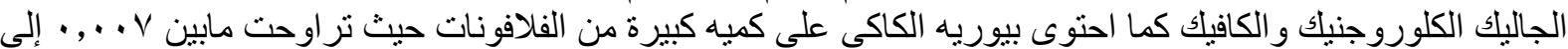

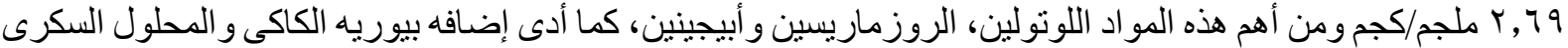

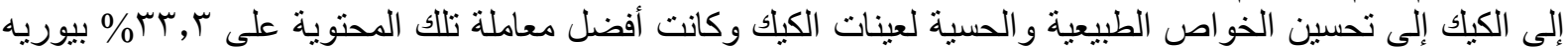

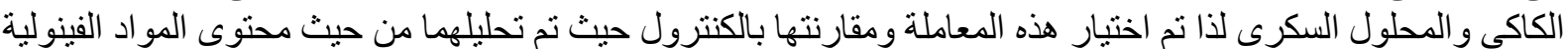

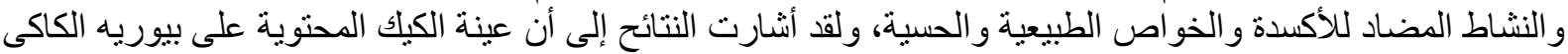

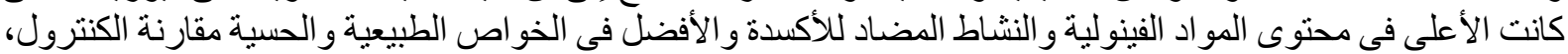

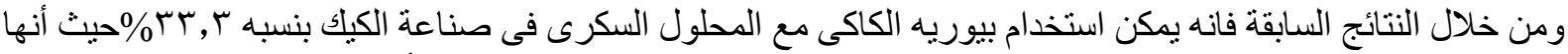

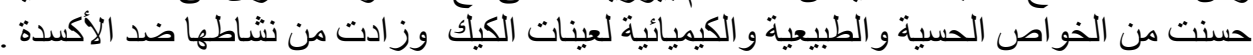

